\title{
Correlation of Posterior Occipitocervical Angle and Surgical Outcomes for Occipitocervical Fusion
}

\author{
Christopher M. Maulucci ${ }^{1}$ George M. Ghobrial ${ }^{1}$ Ashwini D. Sharan ${ }^{1}$ James S. Harrop ${ }^{1}$ Jack I. Jallo ${ }^{1}$ \\ Alexander R. Vaccaro $^{2}$ Srinivas K. Prasad ${ }^{1}$ \\ ${ }^{1}$ Department of Neurosurgery, Thomas Jefferson University, \\ Philadelphia, Pennsylvania, United States \\ 2 Rothman Institute, Philadelphia, Pennsylvania, United States \\ Address for correspondence Christopher M. Maulucci, MD, 909 \\ Walnut Street, 3rd Floor, Philadelphia, PA 19101, United States \\ (e-mail: cmaulucci@gmail.com).
}

Evid Based Spine Care J 2014;5:163-165.

\begin{abstract}
Study Type Retrospective cohort study.

Introduction Craniocervical instability is a surgical disease, most commonly due to rheumatoid arthritis, trauma, erosive pathologies such as tumors and infection, and advanced degeneration. Treatment involves stabilization of the craniovertebral junction by occipitocervical instrumentation and fusion. However, the impact of the fixed occipitocervical angle on surgical outcomes, in particular the need for revision surgery and the incidence of dysphagia, remains unknown. Occipitocervical fusions (OCFs) at a single institution were reviewed to evaluate the relationships between postoperative neck alignment, the need for revision surgery, and dysphagia.

Objective The objective of this study is to determine whether an increased posterior occipital cervical angle results in an increase in the need for revision surgery, and secondary, dysphagia.

Methods A retrospective review of spinal surgery patients from January 2007 to June 2013 was conducted searching for patients who underwent an occipitocervical instrumented fusion utilizing diagnostic and procedural codes. Specifically, a current procedural code of 22590 (arthrodesis, posterior technique [craniocervical]) was queried, as well those with a description of "craniocervical" or "occipitocervical" arthrodesis. Ideal neck alignment before rod placement was judged by the attending surgeon. A review of all cases for revision surgery or evidence of dysphagia was then conducted.

Results From January 2007 to June 2013, 107 patients were identified (31 male, 76 female, mean age 63). Rheumatoid arthritis causing myelopathy was the most common indication for OCF, followed by trauma. Twenty of the patients were lost to follow-up and seven died within the perioperative period. Average follow-up for the remaining 80 patients was 16.4 months. The mean posterior occipitocervical angle (POCA), defined as the angle formed by the intersection of a line drawn tangential to the posterior aspect of the occipital protuberance and a line determined by the posterior aspect of the facets of the third and fourth cervical vertebrae, calculated after stabilization, was 107.1 degrees (range, $72-140$ degrees). Reoperation was required in 11 patients $(11 / 107,10.3 \%)$. The
\end{abstract}

(c) 2014 Georg Thieme Verlag KG Stuttgart · New York
DOI http://dx.doi.org/ 10.1055/s-0034-1386756. ISSN 1663-7976. 
mean POCA for the reoperation group was 109.5 degrees (range, 72-123) and was not significantly different than patients not requiring reoperation (106.5, $p>0.05$ ). However, for all pathologies excluding infection as a cause for reoperation, the mean POCA was significantly higher, 115.14 degrees $(p=0.039)$ ( - Table 1). Seven patients (6.5\%) complained of dysphagia postoperatively with a significantly higher POCA of 115 degrees $(p=0.039)$. Of these seven patients, six underwent posterior-only procedures. One patient underwent anterior and posterior procedures for a severe kyphotic deformity. The dysphagia resolved in six patients over a mean of 3 weeks (range, 24 weeks). One patient, whose surgery was posterior only, required the insertion of a gastrostomy tube.

Conclusions An elevated POCA may result in need for reoperation due to increased biomechanical stress upon adjacent segments or the construct itself due to flexion in an attempt to maintain forward gaze. Further, an elevated POCA seems to also correlate with a higher incidence of dysphagia. Further investigation is necessary to determine the ideal craniocervical angle which is likely individualized to a particular patient based on global and regional spinal alignments.

Table 1 Comparison of occipitocervical fusion patient groups

\begin{tabular}{|l|l|l|l|}
\hline & Revision & No revision & $p$ \\
\hline$N$ & $11(10 \%)$ & $96(89 \%)$ & - \\
\hline POCA & $\begin{array}{l}\text { Mean: } 109.5 \\
\text { Range: } 72-123\end{array}$ & $\begin{array}{l}\text { Mean: } 107.1 \\
\text { Range: } 85-141\end{array}$ \\
\hline Adjacent level disease & Revision (excluding infection as indication) & No revision \\
\hline Instrumentation failure & $2(1.8 \%)$ & & 0.23 \\
\hline Total & $5(4.7 \%)$ & & \\
\hline POCA (degrees) & $7(6.5 \%)$ & $94(88 \%)$ & Mean: 107.1 \\
& Mean: 115 & Range: $85-141$ \\
\hline
\end{tabular}

Note: When patients who underwent revision surgery for reasons other than infection (adjacent segment degeneration or instrumentation failure), a significantly higher POCA (115 degrees, $n=0.039$ ) was found.

\section{Disclosures}

Christopher M. Maulucci, none

George M. Ghobrial, none

Ashwini D. Sharan, Consulting fees: Medtronic; Royalties:

Zimmer

James S. Harrop, Consulting fees: Depuy-Synthes

Jack I. Jallo, none

Alexander R. Vaccaro, Ownership interest in:

BonovoOrthopaedics, Replication Medica, Gamma Spine, Globus Medical, K2 Medical, Orthovita, Paradigm Spine, Progressive Spinal Technologies, Small Bone Innovations, Spinicity, R.I.S., Spine Medica, Stout Medical, Spinology, Flagship Surgical, Innovative Surgical Design; Royalties: Depuy-Synthes, Medtronic, Stryker Spine, Biomet Spine, Globus, Aesculap, and Nuvasive for product development. Honoraria: AOSpine, Spinicity, Innovative Surgical Design, Association of Collaborative Spine Research for Board Membership; Consulting fees: Stout Medical, Orhobullets,
Gerson Lehman Group, Guidepoint Global, Medacorp, and Innovative Surgical Design for consulting

Srinivas K. Prasad, Consulting fee: Stryker; Honorarium: Medtronic, Depuy-Synthes

\section{Note}

This study has been approved by the institutional review board (IRB) of Thomas Jefferson University.

\section{References}

1 Anderson RC, Kan P, Gluf WM, Brockmeyer DL. Long-term maintenance of cervical alignment after occipitocervical and atlantoaxial screw fixation in young children. J Neurosurg 2006;105 (1, Suppl)55-61

2 Ataka H, Tanno T, Miyashita T, Isono S, Yamazaki M. Occipitocervical fusion has potential to improve sleep apnea in patients with 
rheumatoid arthritis and upper cervical lesions. Spine (Phila Pa 1976) 2010;35(19):E971-E975

3 Bagley CA, Witham TF, Pindrik JA, et al. Assuring optimal physiologic craniocervical alignment and avoidance of swallowing-related complications after occipitocervical fusion by preoperative halo vest placement. J Spinal Disord Tech 2009;22(3):170-176

4 Bhatia R, Desouza RM, Bull J, Casey AT. Rigid occipitocervical fixation: indications, outcomes, and complications in the modern era. J Neurosurg Spine 2013;18(4):333-339

5 Deutsch H, Haid RW Jr, Rodts GE Jr, Mummaneni PV. Occipitocervical fixation: long-term results. Spine (Phila Pa 1976) 2005;30(5): 530-535

6 Dickman CA, Papadopoulos SM, Sonntag VK, Spetzler RF, Rekate HL, Drabier J. Traumatic occipitoatlantal dislocations. J Spinal Disord 1993;6(4):300-313

7 Henderson FC, Geddes JF, Crockard HA. Neuropathology of the brainstem and spinal cord in end stage rheumatoid arthritis: implications for treatment. Ann Rheum Dis 1993;52(9):629-637

8 Izeki M, Neo M, Ito $\mathrm{H}$, et al. Reduction of atlantoaxial subluxation causes airway stenosis. Spine (Phila Pa 1976) 2013;38(9):E513-E520

9 Izeki M, Neo M, Takemoto M, et al. The O-C2 angle established at occipito-cervical fusion dictates the patient's destiny in terms of postoperative dyspnea and/or dysphagia. Eur Spine J 2014;23(2): 328-336

10 Kawaida H, Sakou T, Morizono Y. Vertical settling in rheumatoid arthritis. Diagnostic value of the Ranawat and Redlund-Johnell methods. Clin Orthop Relat Res 1989;(239):128-135

11 Lee SC, Chen JF, Lee ST. Clinical experience with rigid occipitocervical fusion in the management of traumatic upper cervical spinal instability. J Clin Neurosci 2006;13(2):193-198

12 Matsunaga S, Ijiri K, Koga $\mathrm{H}$. Results of a longer than 10-year follow-Up of patients with rheumatoid arthritis treated by occipitocervical fusion. Spine (Phila Pa 1976) 2000;25(14):1749-1753

13 Miyata M, Neo M, Fujibayashi S, Ito H, Takemoto M, Nakamura T. OC2 angle as a predictor of dyspnea and/or dysphagia after occipitocervical fusion. Spine (Phila Pa 1976) 2009;34(2):184-188

14 Miyoshi K, Nakamura K, Haga N, Mikami Y. Surgical treatment for atlantoaxial subluxation with myelopathy in spondyloepiphyseal dysplasia congenita. Spine (Phila Pa 1976) 2004;29(21):E488-E491
15 Moskovich R, Crockard HA, Shott S, Ransford AO. Occipitocervical stabilization for myelopathy in patients with rheumatoid arthritis. Implications of not bone-grafting. J Bone Joint Surg Am 2000; 82(3):349-365

16 Nockels RP, Shaffrey CI, Kanter AS, Azeem S, York JE. Occipitocervical fusion with rigid internal fixation: long-term follow-up data in 69 patients. J Neurosurg Spine 2007;7(2):117-123

17 Ota M, Neo M, Aoyama T, et al. Impact of the O-C2 angle on the oropharyngeal space in normal patients. Spine (Phila Pa 1976) 2011;36(11):E720-E726

18 Riel RU, Lee MC, Kirkpatrick JS. Measurement of a posterior occipitocervical fusion angle. J Spinal Disord Tech 2010;23(1): 27-29

19 Sandhu FA, Pait TG, Benzel E, Henderson FC. Occipitocervical fusion for rheumatoid arthritis using the inside-outside stabilization technique. Spine (Phila Pa 1976) 2003;28(4):414-419

20 Singh SK, Rickards L, Apfelbaum RI, Hurlbert RJ, Maiman D, Fehlings MG. Occipitocervical reconstruction with the Ohio Medical Instruments Loop: results of a multicenter evaluation in 30 cases. J Neurosurg 2003;98 (3, Suppl)239-246

21 Sunahara N, Matsunaga S, Mori T, Ijiri K, Sakou T. Clinical course of conservatively managed rheumatoid arthritis patients with myelopathy. Spine (Phila Pa 1976) 1997;22(22):2603-2607, discussion 2608

22 Vaccaro AR, Lim MR, Lee JY. Indications for surgery and stabilization techniques of the occipito-cervical junction. Injury 2005;36 (Suppl 2):B44-B53

23 Visocchi M, Di Rocco F, Meglio M. Craniocervical junction instability: instrumentation and fusion with titanium rods and sublaminar wires. Effectiveness and failures in personal experience. Acta Neurochir (Wien) 2003;145(4):265-272, discussion 272

24 Wang CS, Liu MJ, Lin JH, Xu WH, Luo HB. One stage anteriorposterior approach for traumatic atlantoaxial instability combined with subaxial cervical spinal cord injury. Chin J Traumatol 2011; 14(3):137-142

25 Winegar CD, Lawrence JP, Friel BC, et al. A systematic review of occipital cervical fusion: techniques and outcomes. J Neurosurg Spine 2010;13(1):5-16 